\title{
Analysis of the Coupling Effect of Thermal and Traffic Loads on Cement Concrete Pavement with Voids Repaired with Polymer Grout
}

\author{
Can Cui, ${ }^{1}$ Qing Lu, ${ }^{2}$ Chengchao Guo $\mathbb{D}^{1},{ }^{3}$ and Fuming Wang ${ }^{1}$ \\ ${ }^{1}$ School of Water Conservancy and Environment, Zhengzhou University, Zhengzhou 450001, China \\ ${ }^{2}$ Department of Civil and Environmental Engineering, University of South Florida, Tampa, FL 33620, USA \\ ${ }^{3}$ School of Civil Engineering, Sun Yet-sen University, Guangzhou 510280, China \\ Correspondence should be addressed to Chengchao Guo; canc@usf.edu
}

Received 3 November 2021; Revised 3 December 2021; Accepted 9 December 2021; Published 13 January 2022

Academic Editor: Zhengyang Song

Copyright ( 2022 Can Cui et al. This is an open access article distributed under the Creative Commons Attribution License, which permits unrestricted use, distribution, and reproduction in any medium, provided the original work is properly cited.

Under the repeated action of traffic and thermal loads, a cement concrete pavement slab may partially lose contact with its base course, and voids may develop underneath the slab. Such distress will greatly impact the pavement performance. To fill the voids and restore the base support to the slab, the technology of polymer grouting has been increasingly adopted in recent years due to its advantages of quick application and high efficiency. There is, however, a lack of research on the mechanistic responses and performance of such a repaired rigid pavement under coupled influences of thermal and traffic loads. Existing literature has mainly focused on normal cement concrete pavement structures (i.e., without polymer grouted voids). This study intends to fill the research gap by investigating the time-domain characteristics of thermal stress response of a cement concrete pavement with underlying voids filled with polymer grout, along with design traffic loads. The finite element method was adopted with a 3dimensional nonlinear temperature field within the pavement. A program module was developed in the Abaqus FEA software environment for temperature effect analysis. It was found that under the coupling action of thermal and traffic loads, thermal stress had a greater influence on the critical slab stress at the slab corner than those at other slab locations. Through the comparative analysis before and after polymer grouting repair, the critical tensile stress at the slab corner under the vehicle and thermal loads can be effectively reduced. The polymer performance is stable after three years.

\section{Introduction}

Cement concrete pavement has been widely adopted for roads in China [1] due to its high load bearing capacity. Under repeated vehicle dynamic loading and temperature variation, however, its base course may exhibit plastic deformation. Once the deformation accumulates to a certain point, voids will form underneath a concrete slab and pose one of the major latent risks to the performance of the pavement. If they are not treated in time, the voids may cause premature fracture and damage to the concrete slab due to localized loss of foundation support. To address this issue, grouting has been used to repair and reinforce the voided space. Grouting refers to the use of special mechanical equipment to inject a slurry of filling material into the voids below the slab. After curing, the slurry will form a structural layer with good stability, high strength, and good compactness. Commonly used grouting materials for slab bottom voids may be roughly divided into two categories: organic (e.g., polyurethane, epoxy) and inorganic (e.g., cement-based, cement) [2]. With the development of polymer grouting technology $[3,4]$, the issue of repairing voids underneath cement concrete slabs has been effectively addressed [5].

Recently, Wang et al. $[6,7]$ proposed a new type of nonwater reactive two-component foamed polyurethane polymer grouting materials. The comprehensive properties of the grouting materials are excellent. However, there is a lack of research in the long-term performance of cement concrete pavements with voids repaired with polymer grout, 
the strain and stress responses of the slab, and the polymer grout to the coupled actions of thermal field and traffic loading. Existing literature on rigid pavement behavior under temperature influence is mainly about normal cement concrete pavement structures (i.e., without polymer grouted voids).

A concrete slab will curl when its temperature varies along slab thickness. Typically, the slab curls downwards during the day because its surface temperature is higher than its bottom temperature, while at night, it bends upwards due to a lower surface temperature. Under the influence of slab weight and restraints along the boundary of the slab, stresses may develop in the slab during the thermal curling process. In the AASHO road test [8], it was found that the thermal stresses induced by repeated upward and downward curling would significantly affect the stiffness of the concrete slab $[9,10]$ and the base course of rigid pavement and even lead to slab cracking. Some recent advances in research on thermal stresses and corresponding damages in concrete pavements are reviewed as follows.

Szydło et al. [11] analyzed the temperature distribution and thermal stress parameters of rigid pavements in Poland and estimated the fatigue life of concrete slabs. It was found that with the increase of concrete slab thickness, the temperature-induced tensile stress in the slab first increased and then decreased. Their study established some stress criteria based on the strength of concrete pavement to ensure pavement durability.

$\mathrm{Fu}$ [12] studied the three-dimensional stress state in concrete slabs due to thermal curling and found that the maximum longitudinal tensile stress increased with slab length when the length was between $3 \mathrm{~m}$ and $7 \mathrm{~m}$ but tended to remain stable when the slab length exceeded $8 \mathrm{~m}$. It was also found that the critical thermal curling stress increased with slab thickness when the thickness was less than $22 \mathrm{~cm}$ but decreased with slab thickness when the thickness was greater than $22 \mathrm{~cm}$.

Duan [13] compared the influences of the temperature gradient, slab thickness, and slab stiffness on the thermal stresses in cement concrete slabs and found that the temperature gradient has the most significant effect among the three factors.

Wei et al. [14] did a field study to measure the distributions of temperature and strain along the thickness of concrete slabs in the slab center and corner areas and determined the nonlinearity of strain distribution along slab thickness. They estimated that about $7.4 \%$ of slab area had nonlinear strain distribution along the slab edge and with the nonlinearity decreasing upon approaching the slab center. They measured a drying shrinkage strain of $300 \times 10^{-6}$ at the slab surface and proposed a method to determine the drying shrinkage strain along slab thickness. They also proposed an equation for estimating the nonlinear temperature distribution along slab thickness.

Due to the daily and seasonal variations of air temperature, the thermal stress in a concrete slab fluctuates approximately periodically within a day and a year. The thermal stress fluctuation is more significant at the surface of a slab than that at the slab bottom [15]. Zhang et al. [16] investigated the temperature distribution and stress-strain relationship in the corners of cement concrete pavement slabs in Northeast China. Their results showed that the temperature variation within a slab obviously lagged behind the change of external temperature. At the same point on the top of a slab, the area of the hysteresis loop of temperature and strain increment is larger in the transverse direction than that in the longitudinal direction. The temperature distribution along slab thickness is nonlinear. The nonlinear distribution of thermal along concrete slab thickness and the characteristics of incomplete periodicity of temperature fluctuation during a day all contribute to the obvious hysteresis between temperature and strain increment [17].

Nishizawa et al. [18] proposed a method to predict the thermal stress in concrete slabs based on three-dimensional finite element analysis with one-dimensional thermal stress assumption. Their results showed that the temperature distribution along concrete slab thickness had insignificant nonlinearity in slabs with a thickness of $250-300 \mathrm{~mm}$, but showed obvious nonlinearity in thicker slabs. This is one of the reasons why concrete slabs of $250-300 \mathrm{~mm}$ thick are widely used in Japan. Their method can be used to study the influence of climatic conditions on the fatigue damage of urban rigid pavements.

Through three-dimensional finite element modeling (3DFEM) analysis, Shoukry et al. [19] drew the conclusion that, compared to the horizontal tensile stress that is traditionally used in concrete pavement design, the maximum principal stress is a better indicator of the overall state of stress in the slab, especially when the combined effects of thermal and traffic axle loads are considered. So, in this paper, the trends and characteristics of the maximum principal stress within the slab and the polymer will be mainly analyzed.

This study intends to fill the research gap by investigating the temperature distribution and stress responses of a cement concrete pavement with underlying voids filled with polymer grout under the coupling effect of traffic load. Specifically, this study first formulates the finite element analysis (FEA) of solar-induced temperature field in concrete pavement, then implements the analysis in the off-theshelf software Abaqus FEA by developing a program module for calculating the solar effect. With the developed FEA analysing tool, the temperature field and thermal stress in the concrete pavement are analyzed in detail in terms of the influence of solar radiation, wind speed, air temperature, and material parameters on the solar effect. Traffic load is then introduced into the analysis by applying a cyclic dual wheel load on the pavement through the Dload subroutine of ABAQUS.

\section{Theory and Equations for Thermal Stress Computation}

2.1. External Inputs and Boundary Conditions. Due to the effect of solar radiation, the atmospheric temperature has an obvious variation between day and night and presents periodic change characteristics. The influence of the periodic variation of solar radiation on the temperature field of 
pavement structure can be approximately represented by the periodic boundary conditions.

When a pavement structure is determined, the main environmental factors affecting its temperature field are the total solar radiation $Q$, the effective sunshine time $c$, the maximum temperature $T_{\mathrm{a}}^{\max }$, the minimum temperature $T_{\mathrm{a}}^{\mathrm{min}}$, and the average wind speed $\vartheta_{\omega}$, as discussed below.

2.1.1. Solar Radiation. According to the research results of Yan [20], the daily variation process of solar radiation $q(t)$ can be approximately expressed by the following equation:

$$
q(t)= \begin{cases}0, & 0 \leq t \leq 12-\frac{c}{2}, \\ q_{0} \cos (m \omega(t-12)), & 12-\frac{c}{2} \leq t \leq 12+\frac{c}{2}, \\ 0, & 12+\frac{c}{2} \leq t \leq 24,\end{cases}
$$

where $q(t)=$ solar radiation at time $t\left(\mathrm{~J} / \mathrm{m}^{2} / \mathrm{h}\right)$; $q_{0}=$ maximum radiation at noon $\left(\mathrm{J} / \mathrm{m}^{2} / \mathrm{h}\right), q_{0}=0.13 \mathrm{mQ}$; $t=$ time $(\mathrm{h}) ; \quad m=12 / c ; Q=$ daily solar radiation $\left(\mathrm{J} / \mathrm{m}^{2}\right)$; $c=$ actual effective sunshine period (h); $\omega=$ angular frequency, $\omega=2 \pi / 24(\mathrm{rad} / \mathrm{h})$.

Equation (1) is a piecewise function that has discontinuity. It will bring breakpoints into the temperature field in subsequent calculations. Therefore, it is necessary to convert it into a series form to obtain a smooth and continuous function. This can be achieved using the Fourier polynomial of cosine functions, as shown in equation (2). It was found that a Fourier polynomial of degree 30 can approximate equation (1) with sufficient engineering accuracy.

$$
q(t)=\frac{a_{0}}{2}+\sum_{k=1}^{\infty} a_{k} \cos \frac{k \pi(t-12)}{12}
$$

where $a_{0}=2 q_{0} / m \pi$, and

$$
a_{k}= \begin{cases}\frac{q_{0}}{\pi}\left[\frac{1}{m+k} \sin (m+k) \frac{\pi}{2 m}+\frac{\pi}{2 m}\right], & k=m, \\ \frac{q_{0}}{\pi}\left[\frac{1}{m+k} \sin (m+k) \frac{\pi}{2 m}+\frac{1}{m-k} \sin (m-k) \frac{\pi}{2 m}\right], & k \neq m .\end{cases}
$$

2.1.2. Convective Heat Transfer. Because the thickness of a concrete pavement is small compared to its areal dimensions, the temperature field in the pavement may be approximated by the one-dimensional heat transfer equation, as shown in the following equation [18]:

$$
\rho C \frac{\partial T}{\partial t}=K \frac{\partial^{2} T}{\partial z^{2}}
$$

where $\rho=$ density $\left(\mathrm{kg} / \mathrm{m}^{3}\right) ; C=$ specific heat $(\mathrm{J} / \mathrm{kg} / \mathrm{K})$; $K=$ coefficient of thermal conductivity $(\mathrm{W} / \mathrm{m} / \mathrm{K}) ; z=$ depth from the surface $(\mathrm{m}) ; T=$ temperature in the pavement $(\mathrm{K})$, represented by $T(z, t)$, which is a function of thickness $(z)$ and time $(t)$.

To solve equation (4), the initial condition is given as $T(z$, $0)=T_{0}(z)$, in which $T_{0}(z)$ represents the initial temperature field in the pavement (i.e., at time $t=0$ ). The boundary conditions are given as follows:

$$
\begin{aligned}
& -K \frac{\partial T}{\partial z}=q_{\mathrm{con}}+q_{\mathrm{sol}}+q_{\mathrm{rad}}, \quad \text { when } z=0, \\
& -K \frac{\partial T}{\partial z}=0, \quad \text { when } z=z_{b},
\end{aligned}
$$

where $q_{\text {con }}=$ convective heat flux between the surface and its surrounding air $\left(\mathrm{W} / \mathrm{m}^{2}\right) ; q_{\mathrm{sol}}=$ solar net radiation flux $(\mathrm{W} /$ $\left.\mathrm{m}^{2}\right) ; q_{\mathrm{rad}}=$ infrared net radiation flux $\left(\mathrm{W} / \mathrm{m}^{2}\right) ; z_{b}=$ depth to the layer bottom $(\mathrm{m})$.
Equation (5) shows two boundary conditions, one at the surface and the other at the bottom of the concrete slab.

2.1.3. Radiant Heat Exchange. The long wave radiation and absorption of concrete and other general engineering materials follow the rules of the grey body. According to the Kirchhoff law of thermal radiation, the emissivity $(\varepsilon)$ of a grey body is equal to its absorption rate $(A 1)$ :

$$
A 1=\varepsilon \text {. }
$$

The Kirchhoff law shows that the larger the radiation capacity of an object is, the greater its absorption capacity becomes. The emissivity of the surface of an object depends on material type, surface temperature, and surface condition. The emissivity $(\varepsilon)$ of most nonmetallic materials, however, is very high, generally between 0.85 and 0.95 , and has little to do with the surface condition. For the concrete surface, therefore, its emissivity can be approximated by a value of 0.9 [21].

2.2. Nonlinear Temperature Gradient and Thermal Stress Formulation. The year-around exposure of a cement concrete pavement to the environment often results in a surface temperature of the concrete slab that is usually much higher than the bottom temperature. Such a high temperature 
gradient plays an important role in the upheaval buckling of the pavement [22].

As it is known, the stresses in concrete pavement are caused by repeated wheel loading and varying temperature and moisture gradients. Compared to the stresses calculated based on the traditional linear temperature gradient assumption, the stresses calculated based on a nonlinear temperature gradient can be significantly different [23], particularly in the early morning and at night, with an extreme difference as high as threefold of the values based on the linear temperature gradient.

The stress distribution in a concrete slab due to a nonlinear temperature gradient field may be analyzed following the two-step procedure presented by Mohamed and Hansen [24].

In the first step, residual stresses, as produced internally within the slab to maintain an equilibrium of internal forces due to internal restraints on deformation (i.e., restrains exerted by adjacent elements within the slab to maintain displacement continuity) are calculated. The slab is first considered fully unrestrained and weightless, subjected to a nonlinear temperature gradient $T(z)$, in which $z$ is the depth measured from the slab mid-plane and considered positive downward. The resulting strain distribution $\varepsilon(z)$ equals $\alpha T(z)$, in which $a$ is the thermal expansion coefficient of the slab. The residual normal stress in the longitudinal or transverse direction can be calculated as follows:

$$
\sigma_{\text {res }}=\frac{E}{(1-v)}\left[-\varepsilon(z)+\frac{12 M^{*}}{h^{3}}(-z)+\frac{N^{*}}{h}\right],
$$

where $E$ and $v$ are Young's modulus and Poisson's ratio of the slab, respectively; $h$ is slab thickness.

$$
\begin{aligned}
N^{*} & =\int_{-h / 2}^{h / 2} \varepsilon(z) \mathrm{d} z, \\
M^{*} & =\int_{-h / 2}^{h / 2} \varepsilon(z) z \mathrm{~d} z .
\end{aligned}
$$

In the second step, stresses due to external restraints (slab self-weight and subgrade reaction) on deformation are calculated using an equivalent linear temperature gradient that can produce the same slab curvature as the nonlinear temperature gradient. The temperature difference, $\Delta T_{\text {eq }}$, between the bottom and the top of the slab under the equivalent linear temperature gradient is calculated as follows:

$$
\Delta T_{\mathrm{eq}}=\frac{-\left(12 M^{*}\right)}{\alpha h^{2}} .
$$

The slab curvature, $k$, can be calculated as follows:

$$
k=\frac{\left(12 M^{*}\right)}{h^{3}} \text {. }
$$

Once the equivalent linear temperature gradient is calculated, stresses due to nonlinear temperature gradient and external restraints can be calculated using either closed form solutions such as those by Westergaard or Bradbury [25] or available numerical analysis packages.

The sum of the stresses calculated from the two steps gives the final stress solution.

\section{Establishment of Finite Element Model of Cement Concrete Pavement}

A typical rigid pavement structure, as shown in Figure 1, is selected for the 3DFEM analysis. The surface layer consists of 15 concrete slabs, with each slab being $4 \mathrm{~m}$ wide, $5 \mathrm{~m}$ long, and $0.24 \mathrm{~m}$ thick. Below the concrete slabs is a $0.16 \mathrm{~m}$ thick cement stabilized macadam layer, a $0.16 \mathrm{~m}$ thick stabilized gravel base, and a $3 \mathrm{~m}$ thick soil layer. Tie bars are used along longitudinal joints and dowel bars are used along transverse joints, with a length of $0.41 \mathrm{~m}$, a diameter of $0.026 \mathrm{~m}$, and a spacing of $0.3 \mathrm{~m}$, as shown in Figure 1. This structure was selected because it is consistent with the rigid pavement structure on S24 Expressway in Shandong Province, China, which had voids detected underneath the slabs and subsequently repaired by polymer grouting. It also had field temperature measurements in the pavement structure, as discussed in Section 4.1. A void space, with dimensions of $0.2 \mathrm{~m}$ in length, $0.2 \mathrm{~m}$ in width, and $0.02 \mathrm{~m}$ in height, is included underneath the corner of one middle slab, as marked by the star symbol in Figure 1.

It is critical to choose the mesh size for high accuracy results at a reasonable cost. For the $3 \mathrm{D}$ road model in this paper, we chose hexahedral units as the mesh analysis. For the certain reason that they can generate the best results at the lowest cost. Structured meshing technoly and a secondary deflating integral (CPS8R, CPE8R, C3D20R) were applied in the model.

The interface between the concrete slab and the stabilized macadam base layer is modeled by an interface element that represents the interaction between the slab and the base by three linear springs. No interface element is used within the void area. The rotational displacement of the nodes on the boundary (four sides at transverse and longitudinal) is fixed, while normal displacements in the normal direction are free. All displacements at nodes on the bottom of the structure are fixed. The material parameters of the concrete pavement structure are presented in Table 1.

With the finite element model established, thermal stresses are analyzed in two steps. Firstly, the pavement structure is discretized with a temperature field analysis element type DC3D8 in Abaqus FEA. For given heat transfer boundary conditions, the transient heat transfer analysis is carried out to obtain the temperature field solution. Secondly, with the finite element meshing kept unchanged, the element type is transformed into the corresponding type for stress analysis, which is realized by calling the "heat transfer" command in Abaqus FEA. The boundary condition of the stress problem is determined by using temperature analysis results as the input for the stress analysis. Thermal stress results are then obtained through finite element analysis. 


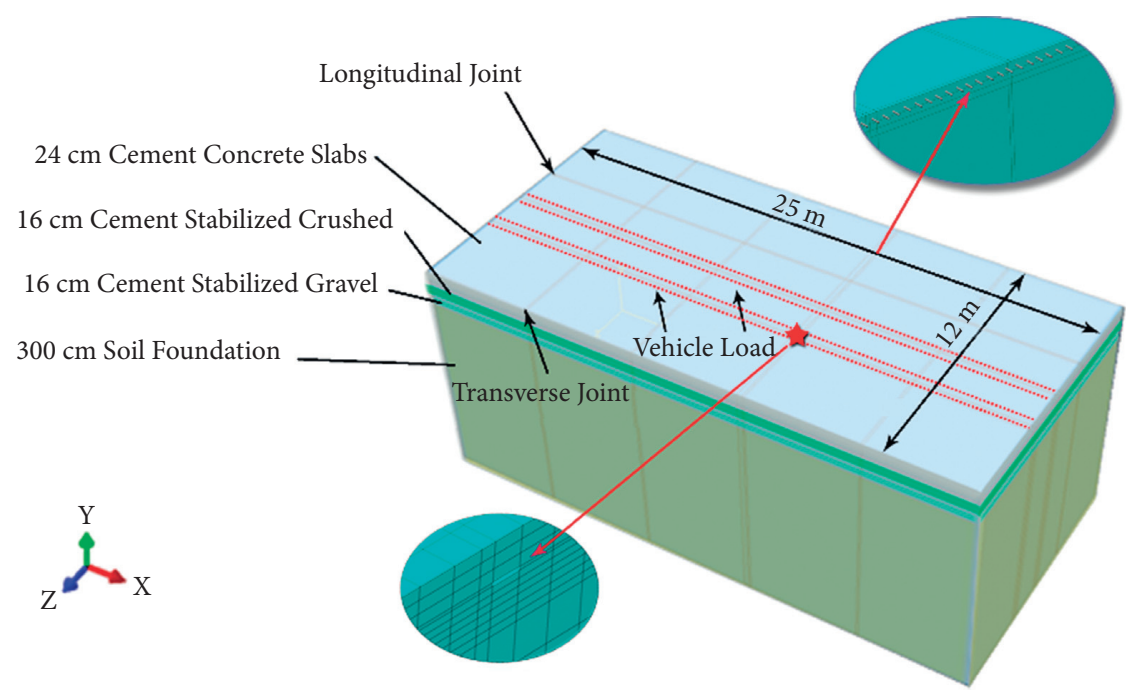

FIGURE 1: Finite element model of concrete pavement structure.

TABle 1: Material parameters of the 3DFEM model.

\begin{tabular}{lccccc}
\hline Structure & Modulus $(\mathrm{MPa})$ & Density $\left(\mathrm{kg} / \mathrm{m}^{3}\right)$ & Poisson's ratio & $\begin{array}{c}\text { Conductivity }(\mathrm{W} / \mathrm{Specific} \mathrm{heat} \\
(\mathrm{m} \cdot \mathrm{K}))\end{array}$ & $\begin{array}{c}\text { Coefficient of } \\
\mathrm{KJ} /\left(\mathrm{kg} \cdot{ }^{\circ} \mathrm{C}\right)\end{array}$ \\
\hline expansion $(1 E-6 / \mathrm{K})$
\end{tabular}

\section{FEA of Temperature and Load Induced Stresses in Concrete Pavement}

4.1. Temperature Field Model Verification and Thermal Stress Analysis. The temperature field model described in Section 2 is first verified with temperature data measured from the field. Specifically, temperature measurements were taken from a rigid pavement in the Yantai section of S24 Weiqing Expressway, which was constructed and opened to traffic in 2000 in China. The rigid pavement has four lanes in two directions and a subbase width of $25.5 \mathrm{~m}$. The historical temperature records are as follows. The annual average air temperature was about 11 to $12^{\circ} \mathrm{C}$. The highest air temperature occurred in August with a monthly average temperature of $24.9^{\circ} \mathrm{C}$, while the lowest air temperature occurred in January with a monthly average temperature of $-3.7^{\circ} \mathrm{C}$. Field measurements show that the maximum road surface temperature reached $67.2^{\circ} \mathrm{C}$ in summer and $42.2^{\circ} \mathrm{C}$ in winter. Research [27] shows that the coupling of low temperatures and vehicle load will produce greater tensile stresses at the slab bottom than that of high temperatures. This paper, therefore, will focus on the coupling of thermal stress and vehicle load in the winter.

Pavement surface temperatures were measured hourly from September 1 in 2017, to April 1 in 2018, with a handheld temperature gauge as shown in Figure 2. Voids underneath concrete slabs were detected by a falling weight deflectometer (FWD) on some chosen slabs. Temperature sensors were embedded in a slab in the section between the milepost of $\mathrm{K} 131+045$ and $\mathrm{K} 131+049$ to measure the temperature within the slab all day long. The installation positions of the sensors are illustrated in Figure 3. Specifically, two sensors with a spacing of $5 \mathrm{~cm}$ were embedded near a slab corner, at $1 \mathrm{~cm}$ below the slab top and $5 \mathrm{~cm}$ from the two vertical edges of the slab corner. Another set of two sensors was embedded at the same positions but $3 \mathrm{~cm}$ above the slab bottom. At the middle of one longitudinal edge of the slab, five temperature sensors were embedded $5 \mathrm{~cm}$ apart from the edge and $1 \mathrm{~cm}, 3 \mathrm{~cm}, 7 \mathrm{~cm}, 13 \mathrm{~cm}, 21 \mathrm{~cm}$ below the slab top, respectively. Another set of five sensors was embedded at the same position with the same distance to the slab top. The impact of the dowel bar or tie bar on the curling stress in the slab was negligible [12]. So, in this section, the dowel bar or tie bar is not included in the analysis.

The measured temperatures are compared with those calculated from the temperature field model using the 3DFEM. One example is shown in Figure 4, for temperatures at both the top and the bottom of a slab on a summer day (9/ $16 / 2017)$ and on a winter day (3/22/2018). As can be seen, the calculated values match well with the measured 


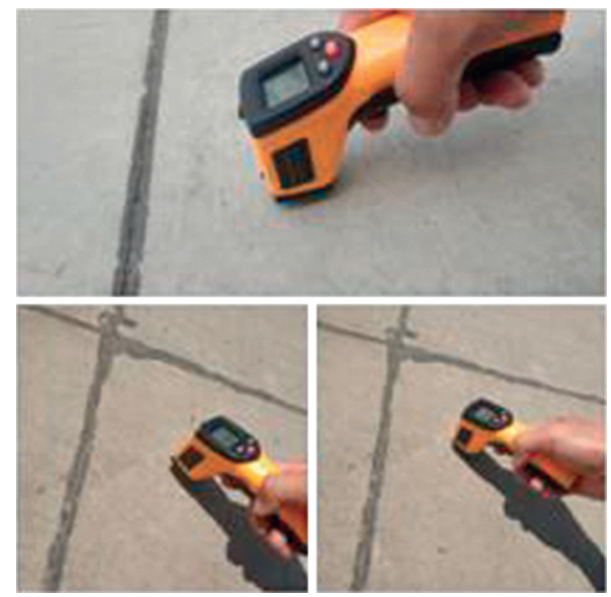

FiguRE 2: On-site daily measurement of pavement surface temperature.

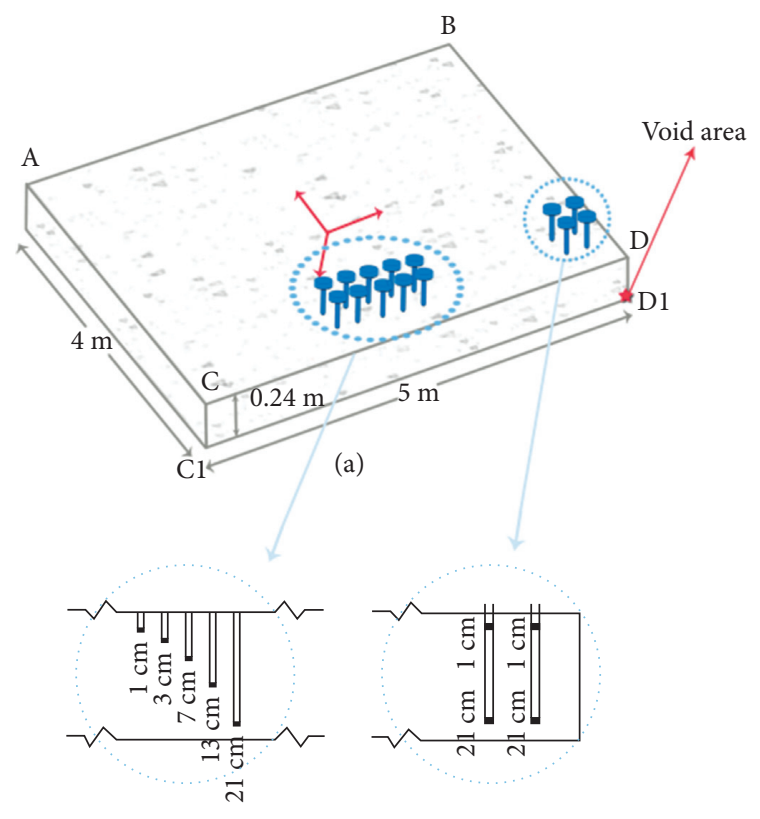

(b)

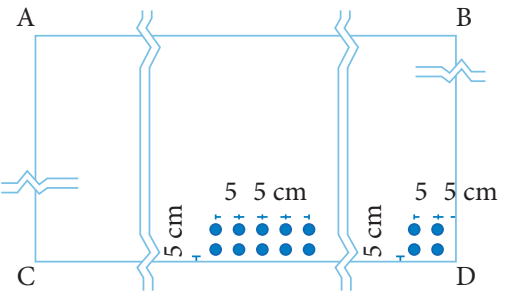

- Temperature seneor

(c)

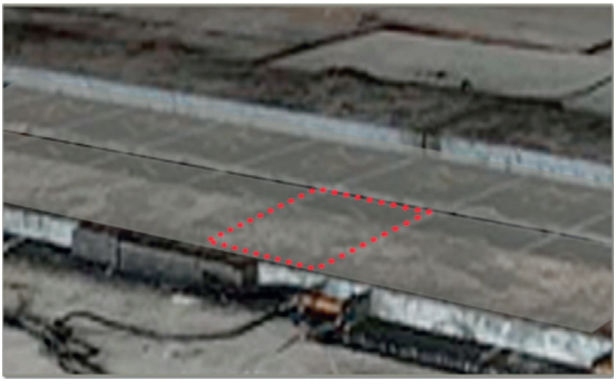

(d)

Figure 3: Positions of temperature sensors in the concrete slab: (a) perspective view, (b) front view, (c) top view, and (d) field picture of testing.

temperatures, suggesting the validity of the adopted temperature model and the 3DFEM analysis.

Figure 5 shows the measured temperature profiles along the slab thickness at different times on March 22, 2018, including 0:00, 4:00, 8:00, 12:00, and 16:00 o'clock. It can be seen that the temperature distribution is nonlinear along slab thickness no matter the time of the day. If the temperature profile is fitted with a straight line, the maximum error from the linear fitting can reach as much as $8^{\circ} \mathrm{C}$. Therefore, using a linear temperature profile in the stress analysis of concrete slabs may underestimate the thermal stress.

The corresponding thermal stresses in the concrete slab due to the above temperature profiles are computed with the 3DFEM analysis. Thermal stresses at the slab corner will be analyzed in the subsequent FEA. The thermal stresses at the corner of a slab in the three working conditions are analyzed for the temperature profiles in summer and winter, respectively. The three working conditions are (1) "normal," in which the concrete slab has full contact with the base; (2) "void," in which there are voids underneath the concrete slab; (3) "polymer," in which the voids underneath the slab are grouted with polymer materials.

The results are shown in Figures 6 and 7, Figures 8 and 9, and Figures 10 and 11 for the normal, void, and polymer conditions, respectively. In these figures, S11 represents the maximum normal stress in the vehicle driving direction $(X$ direction), S22 represents the maximum normal stress in the upward direction ( $Y$ direction), S33 represents the maximum normal stress in the transverse direction ( $Z$ direction), 

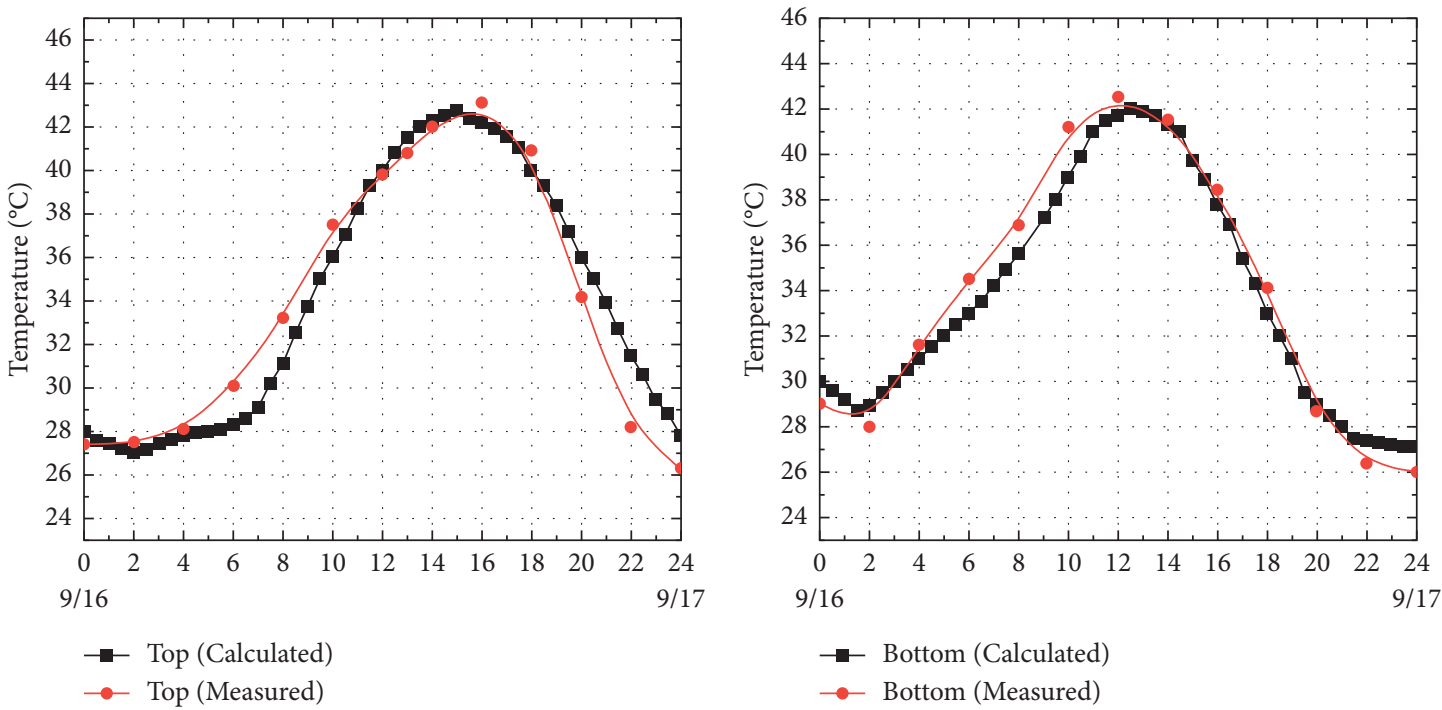

(a)
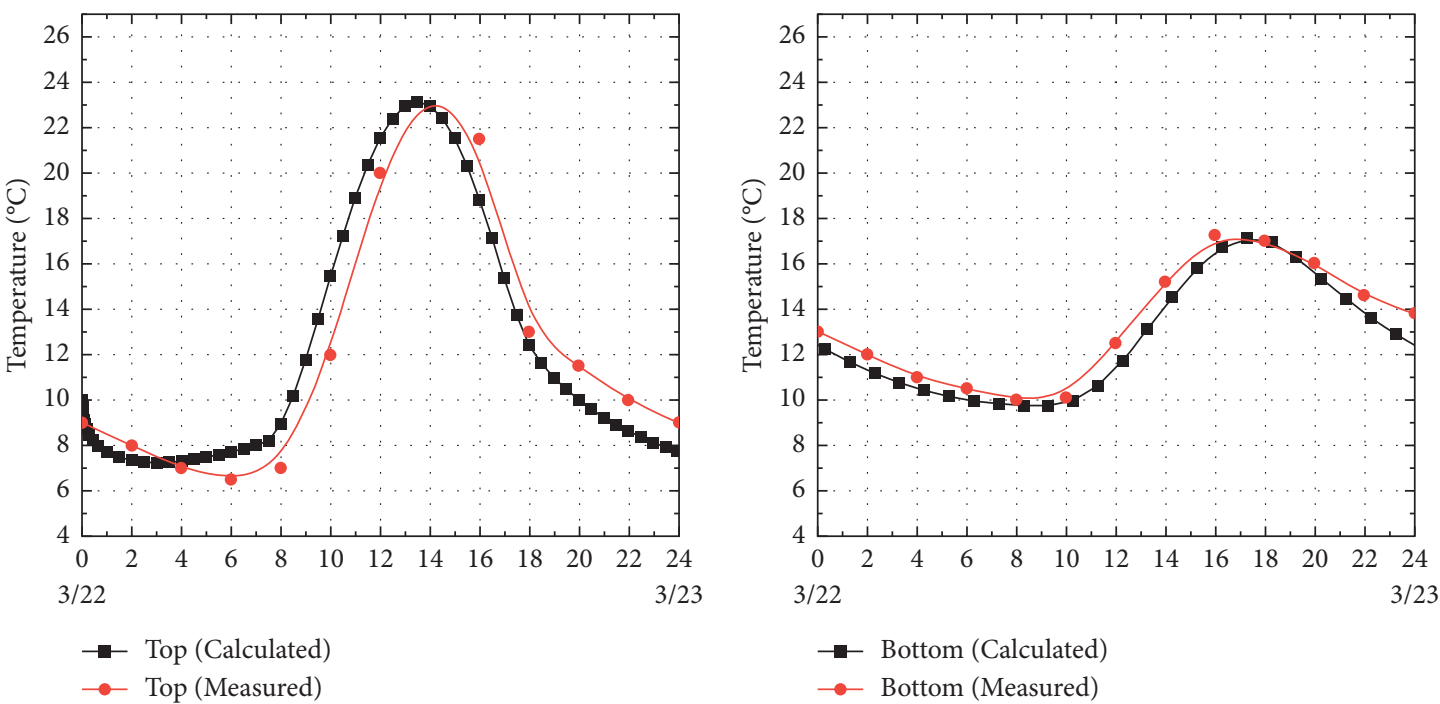

(b)

Figure 4: Comparison of measured and calculated temperatures for a $26 \mathrm{~cm}$ thick slab: (a) summer and (b) winter.

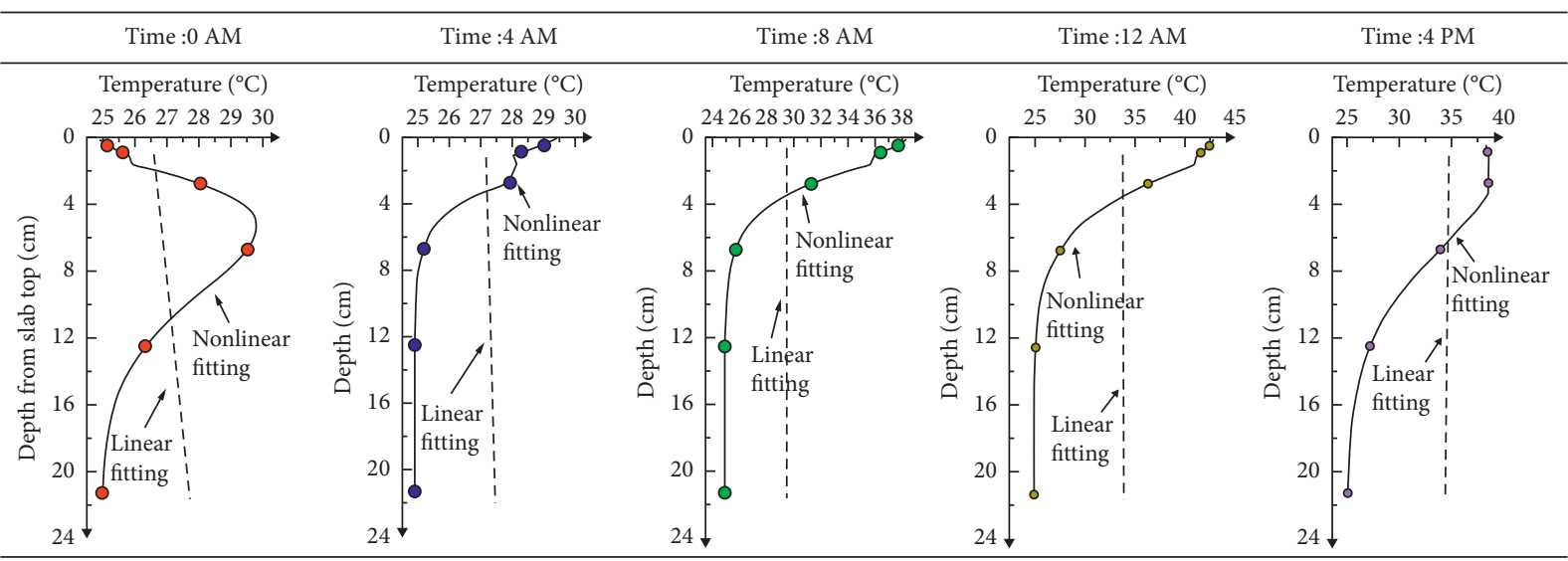

Figure 5: Distribution of temperature along slab thickness at slab corner. 


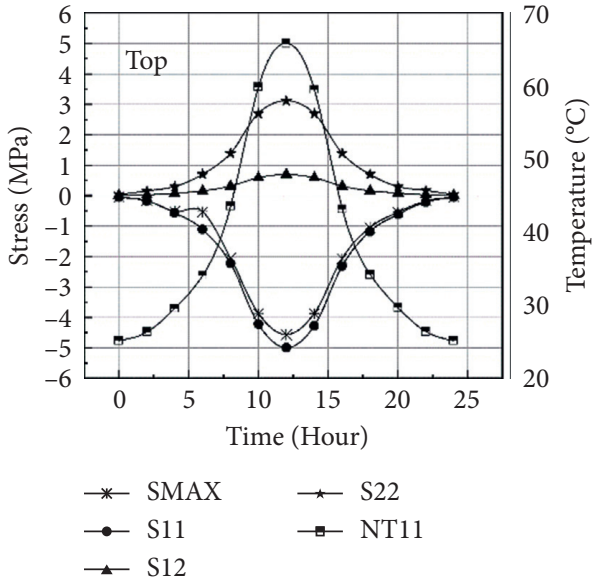

(a)

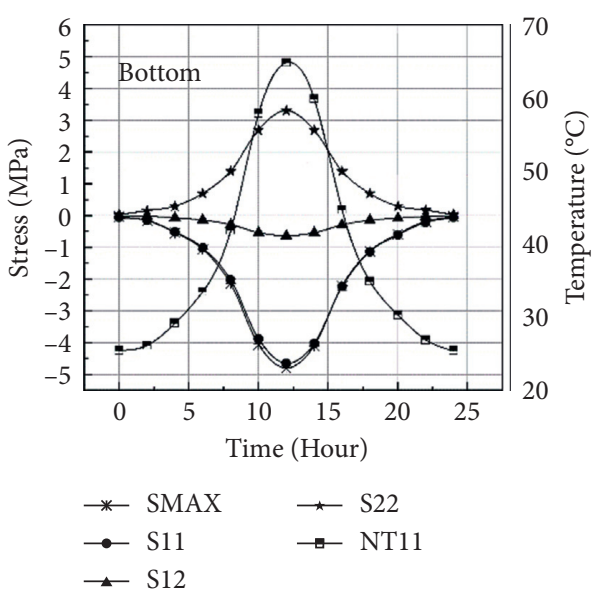

(b)

FIgURE 6: Time-history response curve of stresses above void area in the "normal" condition in the summer: (a) slab top and (b) slab bottom.

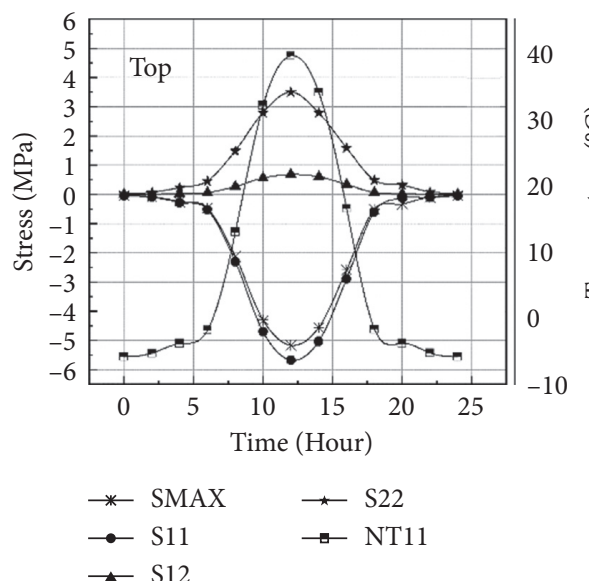

(a)

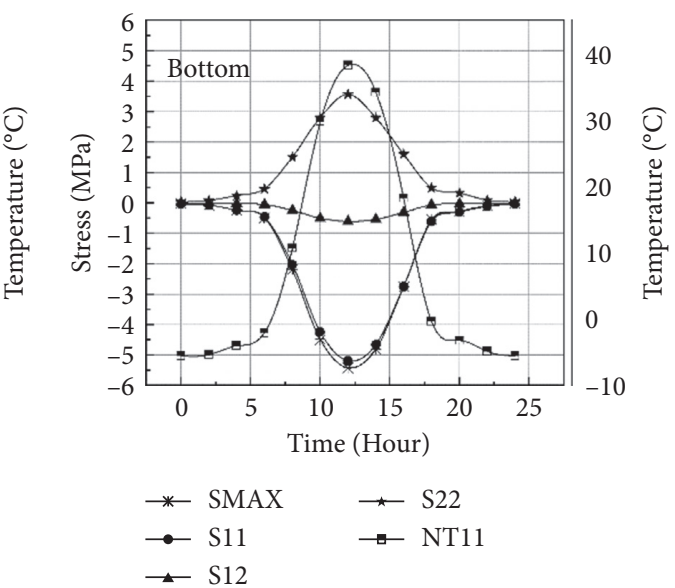

(b)

FIgURE 7: Time-history response curve of stresses above void area in the "normal" condition in the winter: (a) slab top and (b) slab bottom.

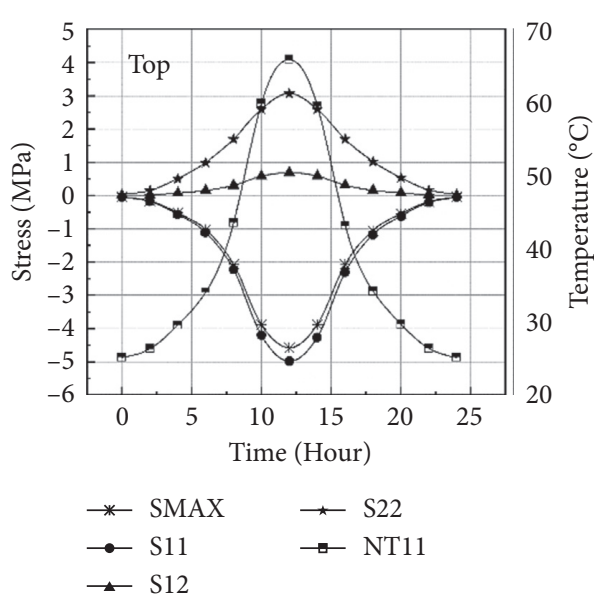

(a)

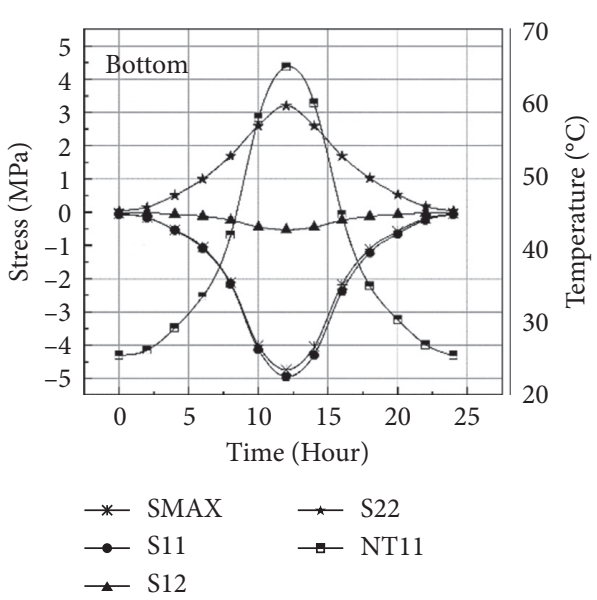

(b)

FIgURE 8: Time-history response curve of stresses above void area in the "void" condition in the summer: (a) slab top and (b) slab bottom. 


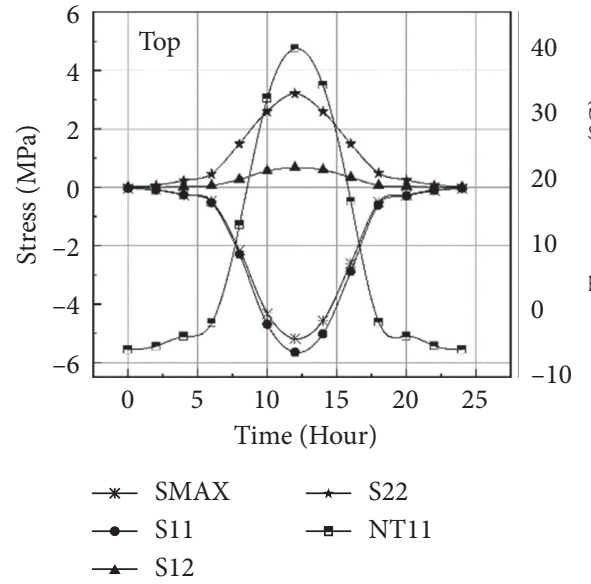

(a)

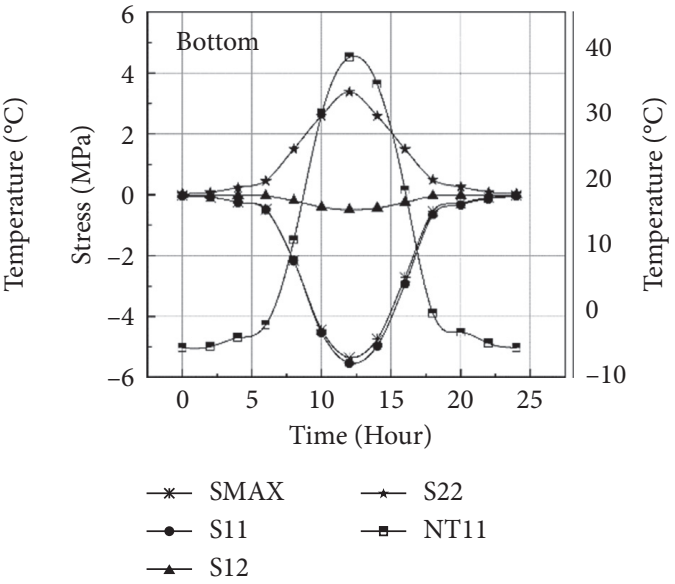

(b)

FIgURE 9: Time-history response curve of stresses above void area in the "void" condition in the winter: (a) slab top and (b) slab bottom.

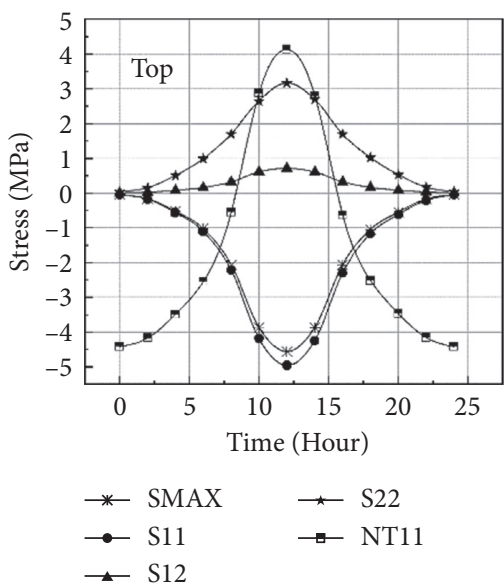

(a)

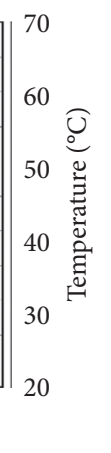

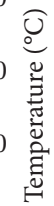
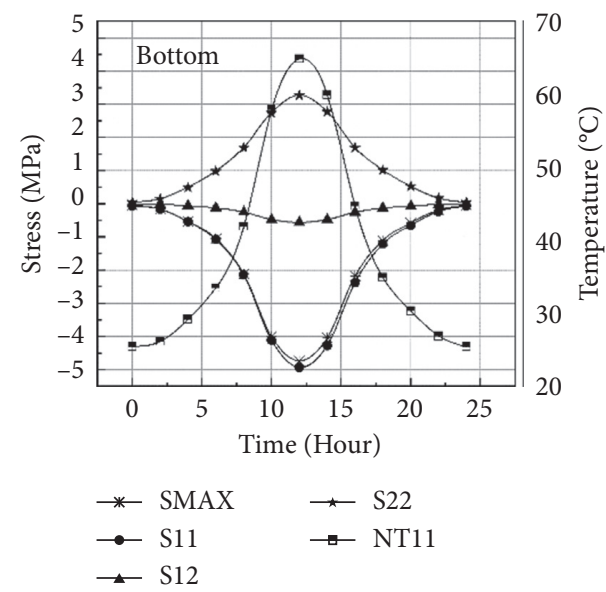

(b)

FIGURE 10: Time-history response curve of stresses above void area in the condition of after polymer grouting in the summer: (a) slab top and (b) slab bottom.

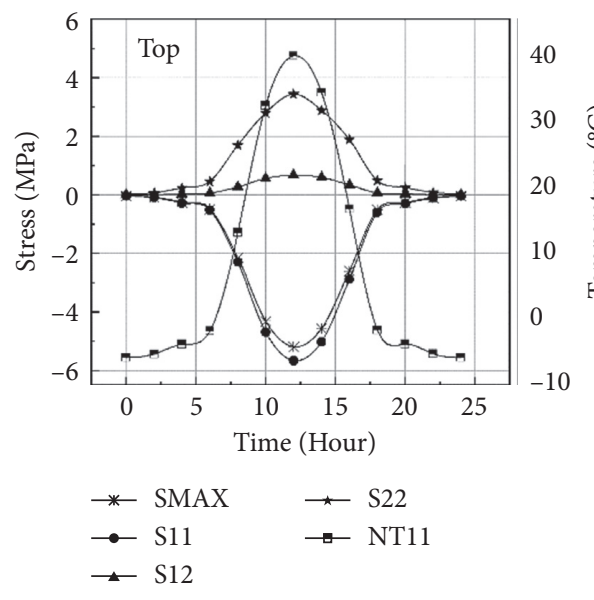

(a)

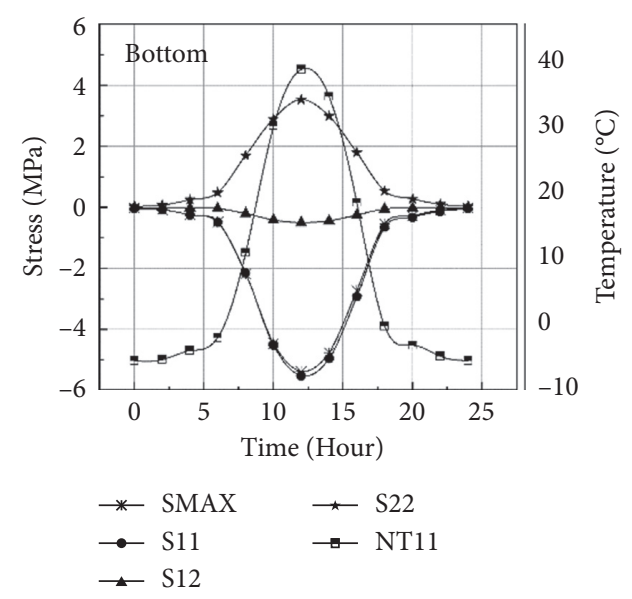

(b)

FIGURE 11: Time-history response curve of stresses above void area in the condition of after polymer grouting in the winter: (a) slab top and (b) slab bottom. 
S12 represents the shear stress on the plane with the normal vector in the $X$ direction and pointing upwards, and SMAX represents the maximum principal stress. The sign convention for normal stress is that negative values represent compression. NT11 represents the variation of temperature calculated at the same point.

Figures 6 and 7 show that, under the thermal stress, the maximum principal stress (SMAX) is negative above the void area in both the summer and the winter, indicating that the maximum compressive stress appears at the slab corner. S11 is a negative value, suggesting compressive stress in the $X$ direction; S22 is positive, suggesting tensile stress in the $Y$ direction. The value of $\mathrm{S} 12$ is positive at the slab top while negative at the slab bottom. The shear stress is very small, varying in the range of $0-0.7 \mathrm{MPa}$. That is because under the thermal stress, a component of the force vector parallel to the pavement cross-section is small. Since the tensile strength of concrete is more sensitive to improper curing than the compressive strength, we focused on investigating the value of tensile stress. In summer, the maximum tensile stress is 3.12 $\mathrm{MPa}$ at the slab top and 3.31 $\mathrm{MPa}$ at the slab bottom. In the winter, the maximum tensile stress is $3.51 \mathrm{MPa}$ at the slab surface and $3.57 \mathrm{MPa}$ at the slab bottom.

The tension to compression ratio for concrete is about 10 to 15 percent. That is, its compressive strength is about 10 times its tensile strength [28]. According to China's specifications for the design of highway cement concrete pavement (JTGD40-2011), the typical maximum tensile strength of C35 cement concrete is $5 \mathrm{MPa}$. Concrete slabs experience higher tensile stress in winter than in summer because, on most of the winter nights, the concrete slab interior has a negative temperature gradient (i.e., the surface temperature is lower than the internal temperature). The concrete slab is like a downward arch whose bottom bears higher tensile stress.

Figures 8 and 9 show that, compared with the "normal" condition, the trend of each stress in the "void" condition is the same but with different extreme values.

In summer, the maximum tensile stress at the slab top is 3.07 $\mathrm{MPa}$, which is lower than that under the "normal" (full contact) condition (3.12 MPa), while the shear stress (S12) remains the same and the maximum principal stress is still compressive. At the slab bottom, the maximum principal stress is $3.21 \mathrm{MPa}$, which is decreased by $0.1 \mathrm{MPa}$ from that under the full contact condition (3.31 MPa); the compressive stress (S11) increased by $0.3 \mathrm{MPa}$. These results indicate that in the high temperature state, the tensile stress decreased and the compressive stress increased at slab bottom in the "void" working condition.

In the winter, the maximum tensile stress at the top of the slab was $3.21 \mathrm{MPa}$, which was $0.3 \mathrm{MPa}$ lower than that in the full contact condition.

In general, regardless of high or low temperature, the critical thermal stress in the slab with the void is lower than that in the full contact condition. The main reason is that when there is a void underneath the slab, the interstice between the slab and the base is increased, which weakens the connection between the pavement and the base. In addition, when the curling deformation occurs, the constraint from the base is reduced, thus causing a reduction in the thermal stress at the corner of the slab.

Figures 10 and 11 show that, after polymer grouting in the void area, the maximum tensile stress at the slab top is 3.17 MPa in summer, which is slightly higher than that under the full contact condition (3.12 $\mathrm{MPa})$, and the maximum tensile stress at the slab bottom is $3.28 \mathrm{MPa}$, which is slightly lower than that under the full contact condition (3.31 MPa). These results indicate that the maximum tensile stresses at both the top and the bottom are reduced after polymer grouting. The reasons that the polymer material can play a good connecting role as the thin filling layer are as follows. Firstly, the polymer material is porous, which can absorb part of the thermal stress during slab curling; Furthermore, the polymer material is temperature inert, so its elastic modulus and volume are in a relatively stable state with the periodic increase and decrease of temperature.

In general, for the three working conditions, the difference between the values of the maximum thermal tensile stresses at the top of the concrete slab is insignificant. This is because the void space adopted in the simulation analysis is small and so the strain transmitted to the slab top from the void space is low. Due to the void space, the connection between the surface layer and the base layer is lost. After that, curling deformation occurs, it would generate seriously under the temperature fluctuations. Therefore, the slab subjected to tensile and compressive action repeatedly can easy to produce cracking damage. After the polymer grouting in the void space, the surface layer and the base layer can be rebonded with increased bonding strength.

4.2. Traffic Load Stress Analysis. Under the action of a continuous moving traffic load, the concrete slab may bend [15]. When the load acts at the center of the slab, the maximum principle stress is compressive at the slab top but tensile at the slab bottom. When the load acts at the corner of the slab, the maximum principle stress is compressive at the slab bottom but tensile at the slab top. It can be seen that under the action of repeated wheel loading, the concrete slab experiences alternating tensile and compressive stresses. It is widely known that the flexural tensile strength of concrete is much lower than its compressive strength. For example, in China, Code for Design of Concrete Structures (GB500102010) [29] shows that C30 concrete has a design flexural tensile strength of $1.43 \mathrm{MPa}$ but a design flexural, compressive strength of $5.0 \mathrm{MPa}$. Therefore, the concrete slab is more prone to cracking damage under tensile stress.

In this section, the critical stresses in the concrete slab induced by moving wheel loading alone are analyzed. A moving (at a speed of $40 \mathrm{~km} / \mathrm{h}$ ) standard single axle load of $100 \mathrm{kN}$, consisting of two wheels on each side of the axle, is applied on the pavement surface with one outer wheel positioned along the edge of the slab with the underlying void, as shown by the red dashed lines in Figure 1. It is well known that such an edge loading scenario leads to critical tensile stresses at the bottom of the concrete slab. The contact pressure between each wheel and the pavement is uniformly distributed on a square area with a value of 
$0.7 \mathrm{MPa}$ and the dual wheels are spaced at $31.95 \mathrm{~cm}$ from the center point to the center point. This standard axle load is used for the design of high classification cement concrete pavement in Chinese specifications. To simulate the effect of repeated moving wheel loading, a haversine load is applied on the slab, with a pressure amplitude of $0.7 \mathrm{MPa}$ and a period of $3.06 \mathrm{~s}$ as determined from the load moving speed $(40 \mathrm{~km} / \mathrm{h})$ and the length of pavement section $(25 \mathrm{~m})$.

When the axle load is placed above the void area at the slab corner, the maximum principal stresses at the top and the bottom of the slab corner are presented in Figure 12 for the three working conditions. It can be seen from Figure 12(a) that when void exists beneath the slab, the maximum principal stress at the slab top corner is tensile with a maximum value of $0.08 \mathrm{MPa}$ (red curve), which is below the concrete tensile strength. After polymer grouting, the maximum principal stress at the void area is compressive stress (blue curve). Figure 12(b) shows that the maximum principal stress at the slab bottom is tensile under all three working conditions, similar to the thermal stress discussed in Section 4.1. The maximum value is about $0.25 \mathrm{MPa}$, which is also less than the concrete tensile strength value.

Figure 13 shows the time history of maximum principal stresses in the concrete slab when the axle load is applied at the middle of the slab longitudinal edge. It can be seen that the maximum principal stress is tensile at the top with a maximum value of $0.72 \mathrm{MPa}$, and the tensile at the bottom with a maximum value of $0.26 \mathrm{MPa}$. Figure $13(\mathrm{~b})$ shows that the magnitude of the load-induced stress is consistent in the three working conditions, but we can see from the plots that the "void condition" has the highest tensile stress value, and the lowest occurs in the "polymer condition." This indicates that polymer grouting can reduce the wheel-load induced critical tensile stress at the slab bottom.

A similar analysis was also performed with the tire/ pavement contact pressure changed to $0.5 \mathrm{MPa}$ and $1.0 \mathrm{MPa}$ to account for under- and overloading scenarios, respectively. Results show that the maximum principal stresses, no matter whether compressive or tensile, are all within the standard ranges allowed in China design specifications [30]. Therefore, no damage would be expected in the concrete slab during its design life under only the traffic load. In reality, however, the pavement is affected by multiple factors, such as traffic load, temperature, and moisture conditions. Therefore, multiple factors need to be coupled in the analysis to gain a more realistic picture of the stress state in the slab.

4.3. Analysis of Combined Effect of Traffic Load and Temperature. In the process of periodic temperature changes, positive and negative temperature gradients alternate in the concrete slab. When the slab is subjected to traffic loads, the thermal and traffic load effects are superimposed. This superimposition effect will be analyzed in this section.

4.3.1. Analysis of Combined Effect of Traffic Load and Temperature in Summer. Assuming that the traffic load is applied on the modeled rigid pavement section repeatedly for 24 hours at a period of $3.06 \mathrm{~s}$, the number of passes in a day is then 28235. Figure 14 shows the maximum tensile stresses at slab corner under the traffic load, thermal effect, and coupled effects under the three working conditions. Curve (1) shows the tensile stress generated from wheelloading, curve (2) shows the maximum tensile stress generated from a thermal effect, and curve (3) is the combined effect of traffic load and temperature.

Figure 14 shows that the traffic induced stress oscillates at a high frequency in 24 hours. Under the normal (full contact) working condition, the traffic induced stress (Figure 14(a) (1)) at the moment when the maximum thermal stress occurs (Figure 15(a)(2)) is negative, indicating that compressive stress is produced at the slab corner under the traffic load, which can neutralize part of the tensile stress due to thermal curling. This is why the extreme value of the total stress $(3.13 \mathrm{MPa})$ is lower than the extreme thermal stress $(3.31 \mathrm{MPa})$ in Figure 14(a). The trend of the total stress is consistent with the trend of the thermal stress, indicating that the thermal stress produces a greater effect.

Under the void working condition (Figure 14(b)), we can see that under the traffic load, significant tensile stress is generated at the slab corner, with an extreme value of $0.31 \mathrm{MPa}$. The extreme thermal stress is lower than that under the normal working condition (curve (2) in Figure 14(a)), indicating that the void area helps relief thermal stress, which is consistent with the results of the previous analysis. The extreme value of tensile stress at the slab corner is $3.79 \mathrm{MPa}$, which is slightly higher than the value due to the thermal effect alone.

It means that the value of the maximum tensile stress generated from the thermal effect decreases slightly in the condition of the void, but the total stress turns higher. At this increased stress, the damage is more easily to occur at the slab corner under repeated traffic and thermal actions. When the bottom of the slab corner is unsupported, the slab is in a cantilever state. After polymer grouting in the void area, the polymer material diffuses in the pores and eventually rebonds the base layer and the concrete slab, for which the calculated stress results are shown in Figure 14(c). It can be seen from Figure 14(c) (2) that, after polymer grouting in the void area, the thermal stress value is slightly increased (from 3.21 to $3.28 \mathrm{MPa}$ ).

Under the coupling effect of load and temperature, the maximum tensile stress in (3) of Figure $14(\mathrm{c})$ is $3.22 \mathrm{MPa}$, a decrease of $17 \%$ compared to $3.79 \mathrm{MPa}$ in the void condition, and a slight increase from $3.13 \mathrm{MPa}$ in the full contact condition. The reason for the maximum tensile stress being slightly higher than that under the full contact condition is that the polymer material has a low modulus of elasticity and its load-carrying capacity is much smaller than that of cement concrete.

In summer, the rank of maximum tensile stresses generated under the three conditions due to thermal effect is, from high to low, full contact ("normal"), after polymer grouting ("polymer"), and void condition. The rank of maximum tensile stresses due to the combined traffic and thermal effects is, from high to low, void condition, after polymer grouting ("polymer"), and full contact. 


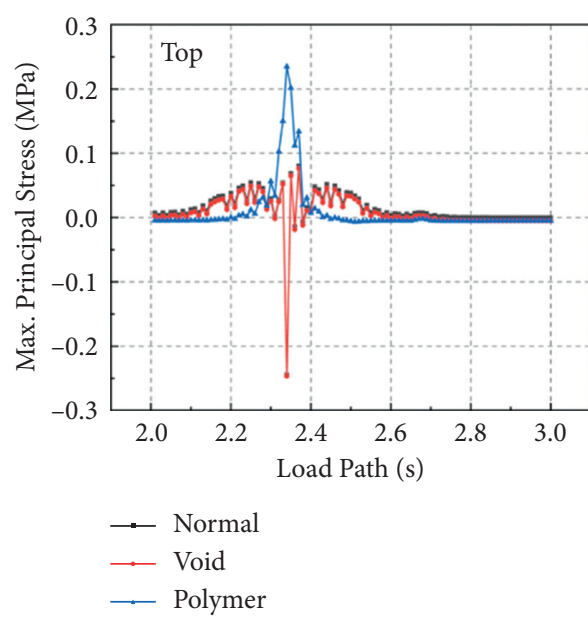

(a)

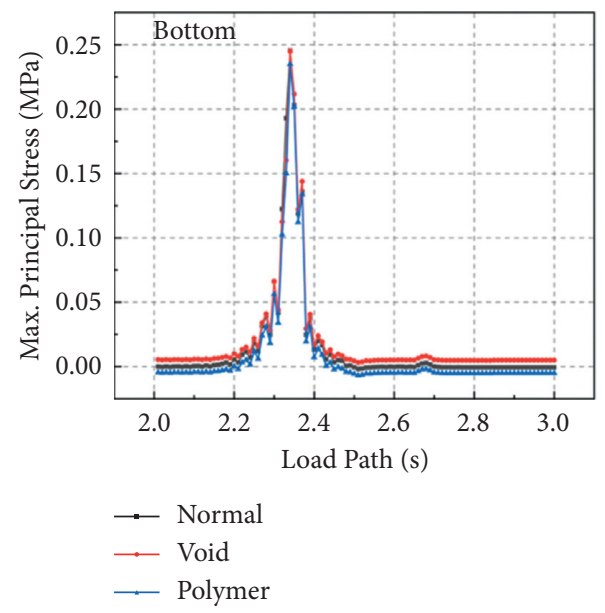

(b)

FIgURE 12: Time-history response curve of maximum principal stress at the slab corner directly above void area: (a) at slab top and (b) at slab bottom.

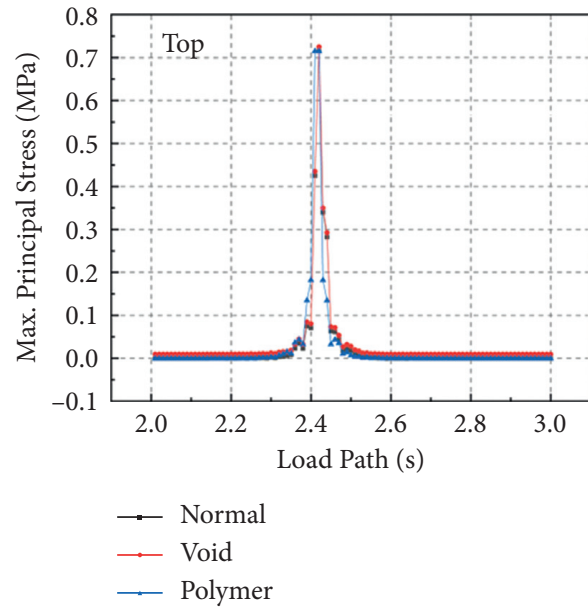

(a)

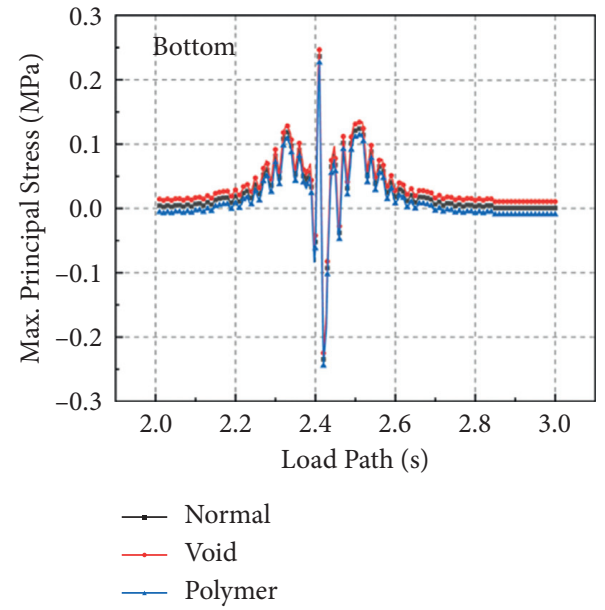

(b)

FIGURE 13: Time-history response curve of maximum principal stress in the middle of slab longitudinal edge: (a) at slab top and (b) at slab bottom.

4.3.2. Analysis of Combined Effect of Traffic Load and Temperature in Winter. In winter, the temperature difference between day and night is large and the temperature gradient within the concrete slab, as shown in the previous calculations, is not always negative but changes in real time with the ambient temperature. The polymer material, therefore, shrinks in volume in winter and its modulus of elasticity increases at lower temperatures. This subsection will analyze the coupled thermal and traffic stresses for the critical winter day when the lowest annual temperature occurs. The analysis period is still 24 hours with the same parameters and three working conditions used in the summer calculation. Traffic load is also the standard single axle load of $100 \mathrm{kN}$ with a contact pressure of $0.7 \mathrm{MPa}$. Results of the maximum tensile stress at the slab corner are presented in Figure 15.
When the concrete slab is in a normal (full contact) condition, from Figure 15(a) (1), it can be seen that under the action of vehicle load, the concrete corner will generate greater tensile stress in winter than in summer. Figure 15(a) (2) shows that the maximum tensile stress generated from thermal effect is also greater in winter $(3.57 \mathrm{MPa})$ than in summer $(3.31 \mathrm{MPa})$, which indicates that under the full contact condition, the maximum thermal stress does not increase with an increased temperature. Figure 15(a) (3) shows that when the traffic load and temperature effects are combined, the maximum tensile stress increases from $3.13 \mathrm{MPa}$ in summer (Figure $14(\mathrm{a})$ (3)) to $3.72 \mathrm{MPa}$ in winter, an $18 \%$ increase. This indicates that the concrete slab is subjected to a higher critical tensile stress in winter than in summer under the coupled effects of vehicle load and temperature. 

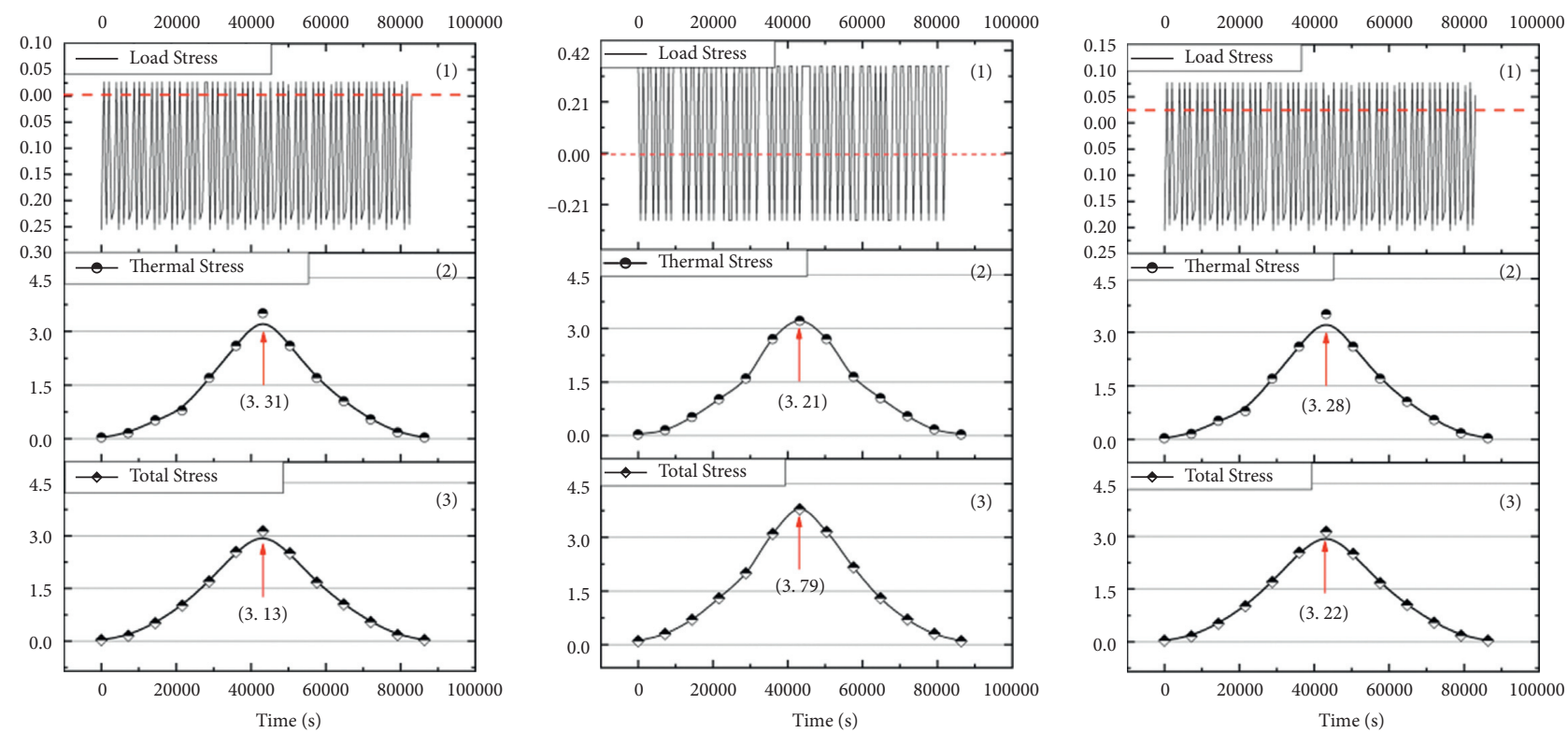

Figure 14: Maximum tensile stress (MPa) at slab corner under the coupling of thermal and traffic loads in summer: (a) "normal" condition, (b) "void" condition, and (c) "polymer" condition.
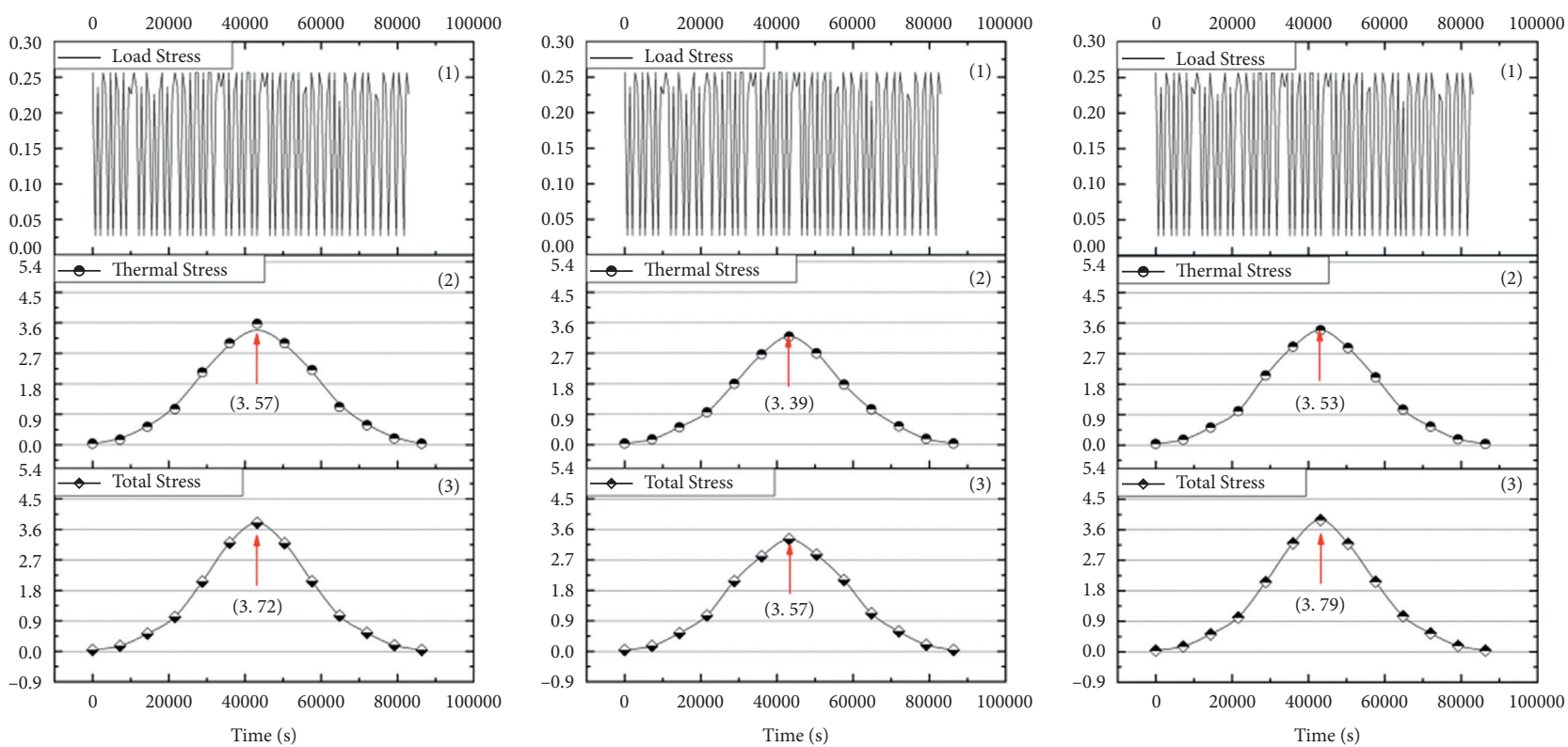

Figure 15: Maximum tensile stress (MPa) at slab corner under the coupling of thermal and traffic loads in winter: (a) "normal" condition, (b) "void" condition, and (c) "polymer" condition.

Figure 15(b) (2) shows that the maximum thermal stress at the slab corner is $3.39 \mathrm{MPa}$ when the slab has an underlying void, which has an increase of $0.18 \mathrm{MPa}$ compared to $3.21 \mathrm{MPa}$ in summer (Figure 14(b) (2)). This indicates that the maximum thermal stress at the bottom of the slab corner is lower in the void condition than that in the full contact condition, in both summer and winter.

Figure 15(b) (3) shows that when there is a void underneath the concrete slab corner, the maximum tensile stress in the concrete slab under the combined effects of traffic load and the temperature reaches $3.57 \mathrm{MPa}$, which is close to the tensile strength of C35 cement concrete. Early cracking damage, therefore, would be expected in the concrete slab. Compared to the summer condition, the maximum tensile stress in winter increased by $20.5 \%$. Therefore, in order to reduce pavement damage, heavy and overloaded vehicles should be prohibited from concrete slabs with underlying voids, particularly in the low temperature environment.

After the polymer grouting, it can be seen from Figure 15(c) (2) that the maximum thermal stress is 3.53 MPa, which has an increase of $0.14 \mathrm{MPa}$ compared to 


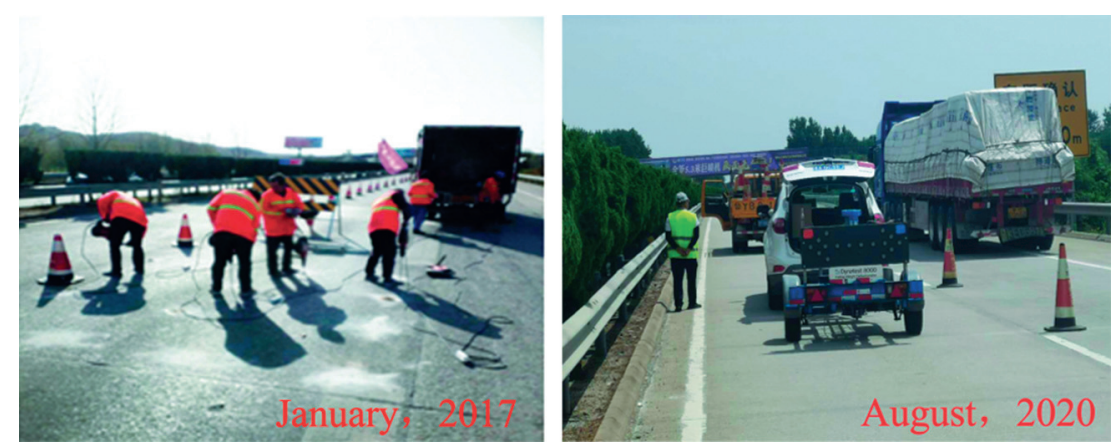

FIgURE 16: Grouting repair and deflection test.

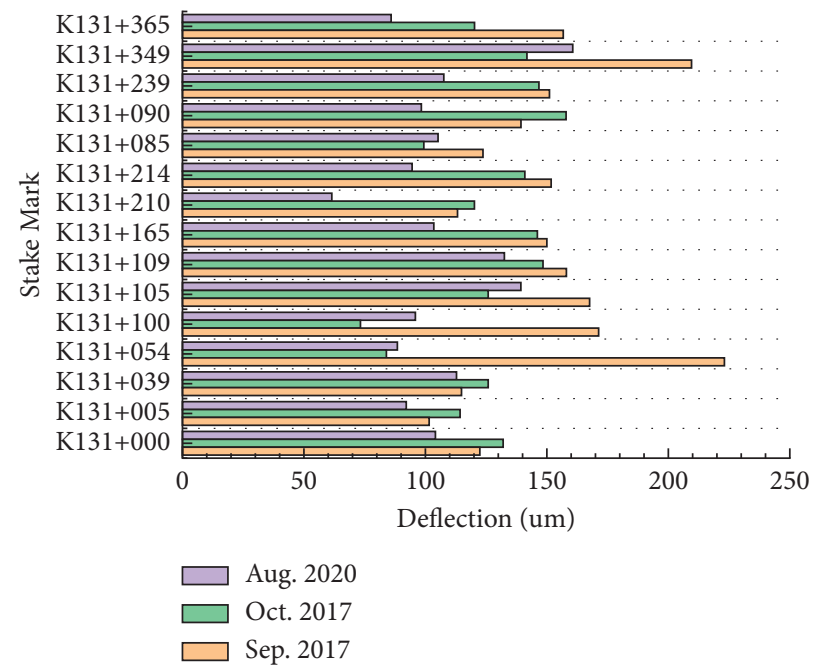

Figure 17: Comparison of average deflections measured in three tests with a $5 \mathrm{~T}$ load.

that $(3.39 \mathrm{MPa})$ in the void condition, but a decrease of $0.04 \mathrm{MPa}$ compared to that $(3.57 \mathrm{MPa})$ in the full contact condition. Figure 15(c) (3) shows that polymer grouting reduces the maximum tensile stress under the combined effects of vehicle load and temperature from $4.57 \mathrm{MPa}$ (void condition) to $3.79 \mathrm{MPa}$, which is a $28 \%$ reduction. Compared to the stress reduction percentage $(17 \%)$ in summer, the polymer material performance seems to be better in winter.

In winter, the rank of maximum tensile stresses generated under the three conditions due to thermal effect is, from high to low, full contact ("normal"), after polymer grouting ("polymer"), and void condition. The rank of maximum tensile stresses due to the combined traffic and thermal effects is, from high to low, void condition, after polymer grouting ("polymer"), and full contact. These ranks are identical to those in summer.

\section{Field Case Study}

This study is based on the project of restoring the performance of cement concrete pavement of S24 Weiqing Expressway in Shandong Province, China, by repairing the void underneath the slab with polymer grouting. The grouting repair was finished in January 2017 in the section of
$\mathrm{K} 130+950 \sim \mathrm{K} 163+882$. Pavement performance was evaluated by a fall weight deflection test before and after polymer grouting, as shown in Figure 16.

The deflection tests were conducted with an impact load of 5, 7, and $9 \mathrm{~T}$ (metric ton) (i.e., 49.0, 68.6, and $88.2 \mathrm{kN}$ ) at the slab right corner, about $0.25 \mathrm{~m}$ from the slab edge, on September 14, 2017, October 13, 2017, and August 14, 2020, respectively. The average deflection results from the three tests (before, right after, and three years after grouting) are summarized in Figures 17-19 for the three impact loads, respectively. The 15-kilometer posts in these figures were selected randomly.

Figure 17 shows that under an impact load of $5 \mathrm{~T}$, which applies a pressure of $690-710 \mathrm{kPa}$, the deflection values after treatment were higher than those before treatment in 5 out of 15 data sets. This is probably due to the fact that the curing of the polymer material has not yet been completed in the process of void diffusion and has not yet reached the design strength. The deflection values measured three years later, however, are all lower than the initial test values, with a decrease rate in the range of $9-45 \%$. Compared to the deflections measured right after polymer grouting, the deflections measured three years later increased in 5 groups and decreased in 10 groups, with an increase rate of $5-11 \%$ and a decrease rate of $11-60 \%$. 


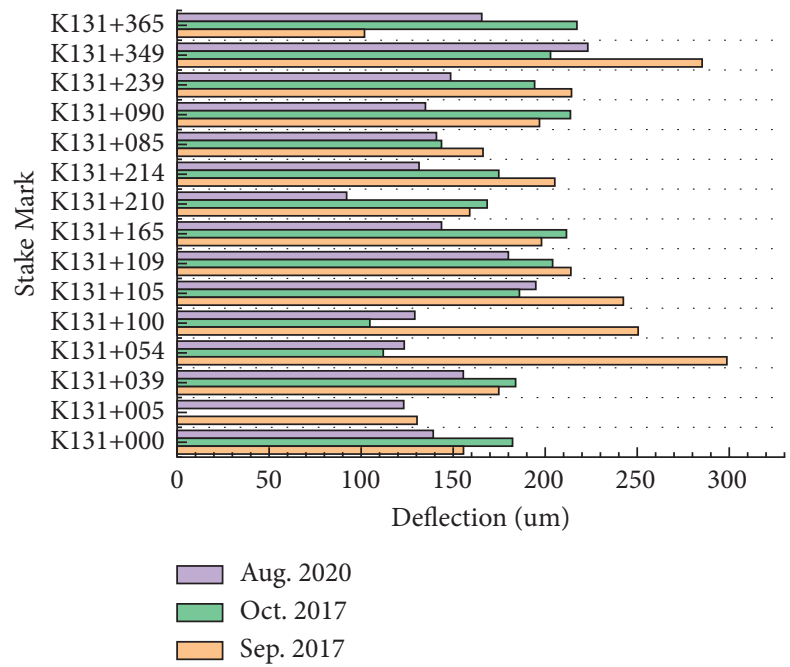

FIgURE 18: Comparison of average deflections measured in three tests with a $7 \mathrm{~T}$ load.

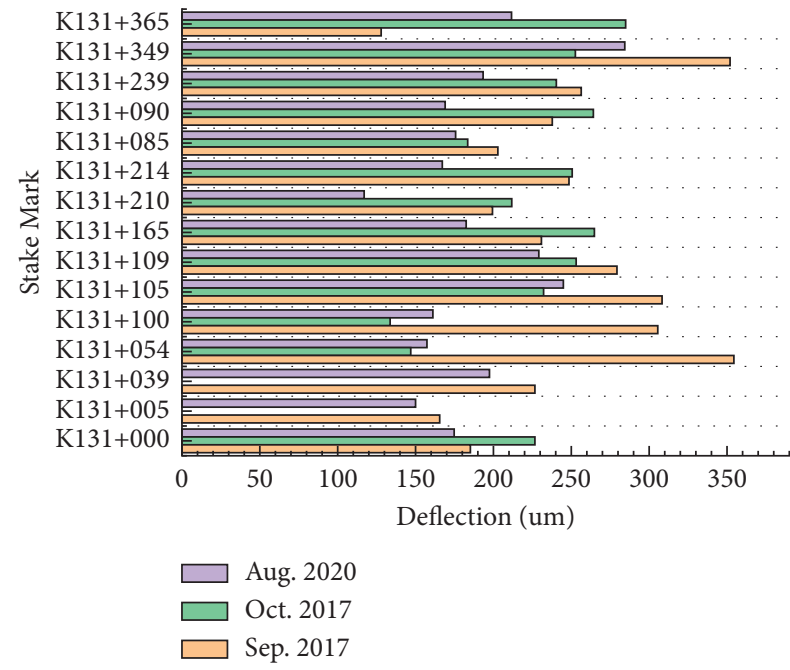

Figure 19: Comparison of average deflections measured in three tests with a $9 \mathrm{~T}$ load.

Figure 18 shows that under an impact load of $7 \mathrm{~T}$, which applies a pressure of $975-1100 \mathrm{kPa}$, the deflection values after treatment were higher than those before treatment in 6 out of 15 data sets, with the percentage higher being $5-17 \%$. The results of the 15 data sets after three years show that they are all lower than the initial detection values. The overall analysis shows that the deflection values after three years under the $7 \mathrm{~T}$ load decreased from the initial test values, with the decrease rate ranging from $5 \%$ to $58 \%$. Compared to the deflection values right after polymer grouting, the deflection values measured three years later increased in 4 groups and decreased in 11 groups, with the increase rate ranging from $4 \%$ to $10 \%$ and the decrease rate ranging from $1 \%$ to $45 \%$.

Figure 19 shows that under an impact load of $9 \mathrm{~T}$, which applies a pressure of $1280-1310 \mathrm{kPa}$, in 8 out of 15 data sets, the deflection values were $2-18 \%$ higher than those before treatment. Three years later, the deflection results of the 8 sets all became lower than the initial test values. The overall analysis shows the deflection values after three years decreased compared with the initial test values, with a decrease rate of $5-55 \%$. Compared to the deflection values right after polymer grouting, 4 groups of values increased, and 11 groups decreased, with an increase rate of $7-20 \%$ and a decrease rate of $7-44 \%$.

As a summary, under the three load levels, the deflection values after treatment decreased by $20.3 \%, 11.6 \%$, and $8.3 \%$, respectively, compared to those before treatment. The deflection values measured three years later decreased by $18.57 \%, 20.5 \%$, and $20.7 \%$, respectively, compared to those after treatment. After three years, the performance of the polymer grouting repair is stable, and it shows a trend that the greater the load, the better the stability.

\section{Conclusions}

This study focuses on the stress analysis in a rigid pavement with voids underlying the concrete slabs before and after repairing with polymer grout, under the coupled effects of thermal and traffic loads. A 3D finite element model (3DFEM) is constructed in the Abaqus FEA environment with field temperature data collected for model validation and with user subroutines (Pave3D and Dload) compiled for stress analysis. Conclusions are summarized as follows.

(1) The temperature changes along the thickness of the concrete slab shows a nonlinear trend. A linear temperature distribution assumption may lead to a maximum error of $8^{\circ} \mathrm{C}$.

(2) Under the impact of thermal and traffic loads, the thermal stress outweighs the traffic load stress in the concrete slab.

(3) At low temperatures, the coupling of load stress and thermal stress will produce greater total stress at higher temperatures. Low temperature and heavy loads will be the most unfavorable combination for the pavement and should be avoided in actual engineering. 
(4) Through the comparative analysis before and after polymer grouting repair, the critical tensile stress at the slab corner under the vehicle load can be effectively reduced by about $19 \%$, and the thermal stress in the void area can be reduced by about $25.9 \%$. The long-term effect of polymer grouting repair was verified in the field case study.

(5) The field case study shows that polymer grouting may initially reduce slab corner deflection in $57.7 \%$ locations and in all locations after three years. The decrease rates of the deflection values after three years are $18.57 \%, 20.5 \%$, and $20.7 \%$ for three impact loads $(5,7$, and $9 \mathrm{~T})$, respectively. The polymer performance is stable after three years and there is a trend that the greater the load is, the better the stability is.

From this study, the advantages of polymer grouting in repairing voids underneath concrete slabs are explained from the mechanism of stress response of slabs to the coupled actions of thermal and traffic loads. This study fills the research gap in the analysis of concrete pavement with underlying voids repaired with polyurethane materials. Findings from this study will need to be further verified with data collected from long-term performance monitoring and testing of rigid pavements whose underlying voids are fixed with polymer grouting.

\section{Data Availability}

The data used to support the findings of this study are included within the article.

\section{Conflicts of Interest}

The authors declare that they have no conflicts of interest.

\section{References}

[1] National Bureau of Statistics, China Statistical Yearbook, National Bureau of Statistics, China, 2019.

[2] H. Chunhua and S. Shuangshuang, "Summary of the grouting material for the void beneath cement concrete pavement slab," IOP Conference Series: Materials Science and Engineering, vol. 382, Article ID 022096, 2018.

[3] M. S. Shi, X. Y. Ma, and F. M. Wang, "Application of polymer grouting technology in cement concrete road repair," Henan Science, vol. 28, pp. 74-77, 2010.

[4] X. Du, H. Fang, S. Wang, B. Xue, and F. Wang, "Experimental and practical investigation of the sealing efficiency of cement grouting in tortuous fractures with flowing water," Tunnelling and Underground Space Technology, vol. 108, Article ID 103693, 2021.

[5] C. C. Guo, F. M. Wang, and Y. H. Zhong, "Research on cement concrete pavement de-voiding polymer grouting technology," Highways, vol. 10, pp. 232-236, 2008.

[6] F. M. Wang, Y. F. Fan, and C. C. Guo, "Non-water reactive polymer grouting water seepage treatment engineering practice," Journal of Hydroelectricity, vol. 37, pp. 1-11, 2018.

[7] F. M. Wang, J. Li, M. S. Shi, and C. C. Guo, "Research and application of new technology for dam seepage control and reinforcement," Journal of Hydroelectricity, vol. 35, no. 12, 2016.

[8] D. J. Van Vuren, Presented at the Third International Conference on the Structural Design of Asphalt Pavements, University of Michigan, Ann Arbor, MI, USA, 1972.

[9] Z. Zhou, X. Cai, X. Li, W. Cao, and X. Du, "Dynamic response and energy evolution of sandstone under coupled static-dynamic compression: insights from experimental study into deep rock engineering applications," Rock Mechanics and Rock Engineering, vol. 53, no. 3, pp. 1305-1331, 2020.

[10] X. Cai, Z. Zhou, L. Tan, H. Zang, and Z. Song, "Fracture behavior and damage mechanisms of sandstone subjected to wetting-drying cycles," Engineering Fracture Mechanics, vol. 234, Article ID 107109, 2020.

[11] A. Szydło and P. Mackiewicz, "Influence of temperature on fatigue life or reinforced pavement by whitetopping: IOP Conference Series," Materials Science and Engineering, vol. 356, p. 12015, 2018.

[12] J. L. Fu, Study on the Dimensional Effect of Temperature Warpage Stress in concrete Pavement Panels, Shandong Traffic Technology, Tai'an, China, 2017.

[13] X. Duan, Finite Element Analysis Study of Temperature Stresses in concrete Pavement Decoupled Slab Angles, Chongqing Jiaotong University, Chongqing, China, 2016.

[14] Y. Wei, X. Gao, F. Wang, and Y. Zhong, "Nonlinear strain distribution in a field-instrumented concrete pavement slab in response to environmental effects," Road Materials and Pavement Design, vol. 20, no. 2, pp. 367-380, 2019.

[15] Q. Xue, L. Liu, Y. Zhao, Y.-J. Chen, and J.-S. Li, "Dynamic behavior of asphalt pavement structure under temperaturestress coupled loading," Applied Thermal Engineering, vol. 53, no. 1, pp. 1-7, 2013.

[16] W. Z. Zhang, B. S. Xu, B. Li, L. H. Yang, and W. Y. Lian, "Experimental study on temperature warpage of airport concrete road surface in Northeast China," Journal of Central South University, vol. 49, pp. 2308-2315, 2018.

[17] Z. M. Tan and Z. K. Yao, "Temperature stresses in cement concrete pavements under nonlinear temperature field," Chinese Journal of Highways, vol. 4, pp. 9-17, 1993.

[18] T. Nishizawa, M. Koyanagawa, Y. Takeuchi, K. Kubo, and T. Yoshimoto, "Thermal stress calculation method for concrete pavement based on temperature prediction and finite element method analysis," Transportation Research Record: Journal of the Transportation Research Board, vol. 2640, no. 1, pp. 104-114, 2017.

[19] S. N. Shoukry, M. Fahmy, J. Prucz, and G. William, "Validation of 3DFE analysis of rigid pavement dynamic response to moving traffic and nonlinear temperature gradient effects," International Journal of Geomechanics, vol. 7, no. 1, pp. 16-24, 2007.

[20] Z. Yan, "Temperature field analysis of layered pavement system," Journal of Tongji University, vol. 3, 1994.

[21] Y. S. Peng, "Theory and application of daylighting temperature effect on concrete bridge structures," 2007.

[22] G. Yang and M. A. Bradford, "Thermal-induced upheaval buckling of concrete pavements incorporating the effects of temperature gradient," Engineering Structures, vol. 164, pp. 316-324, 2018.

[23] M. Dittmanna, F. Aldakheelb, J. Schultea et al., "Phase-field modeling of porous-ductile fracture in nonlinear thermoelasto-plastic solids," Computer Methods in Applied Mechanics and Engineering, vol. 361, pp. 1-25, 2020.

[24] A. R. Mohamed and W. Hansen, "Prediction of stresses in concrete pavements subjected to nonlinear gradients," 
Cement and Concrete Composites, vol. 18, no. 6, pp. 381-387, 1996.

[25] R. Pang, B. Xu, Y. Zhou, X. Zhang, and X. Wang, "Fragility analysis of high CFRDs subjected to mainshock-aftershock sequences based on plastic failure," Engineering Structures, vol. 206, Article ID 110152, 2020.

[26] Z. Song, Y. Wang, H. Konietzky, and X. Cai, "Mechanical behavior of marble exposed to freeze-thaw-fatigue loading," International Journal of Rock Mechanics and Mining Sciences, vol. 138, Article ID 104648, 2021.

[27] C. Ye, Q. Wang, and Y. B. Ding, "Analysis of factors influencing fatigue life of cement concrete pavement under dehollowing coupling," Highways, vol. 63, pp. 100-105, 2018.

[28] S. Shang and Y. Song, "Dynamic biaxial tensile-compressive strength and failure criterion of plain concrete," Construction and Building Materials, vol. 40, pp. 322-329, 2013.

[29] National Standards of the People's Republic of China, Concrete Structure Design Specification (GB50010-2010) 2010, Chinese Standard.net, China, 2010.

[30] China Construction Standard Highway Committee, Technical Standards for Highway Engineering (JTG B01-2014), Chinese Standard.net, China, 2014. 